\title{
Assessment of the conducted bookkeeping training programs by the Apayao State College
}

\author{
Dr. Randy A. Cabilatazan* \\ bsba81803@gmail.com \\ Malama, Conner, Apayao, 3807 Philippines
}

\begin{abstract}
To assess the conducted bookkeeping training programs of the Apayao State College, a descriptive survey method was used. To described the profile of the respondents in terms of age, sex, civil status, religion and highest educational attainment and determine the assessment of the training program as to learner reaction, learning, behaviour, results and work efficiency. The study was conducted in Conner, Apayao and made use of a questionnaire which consisted of three (3) parts. Respondents were selected through total enumeration. Frequency and percentage distribution and weighted mean accompanied by 4 point Likert Scale were used. Findings revealed that the profile of the respondents were adult, female, married, practiced non-Catholic faith and bachelor's degree holders. Respondents affirmed positively on learner reaction and learning. Moreover, their behaviour and work efficiency have improved after the training. Thus, it was concluded that the bookkeeping training programs was effectively conducted. However, there are still areas that need to be enhanced or improved to strengthen the conduct of bookkeeping trainings in the future.
\end{abstract}

Keywords: training effectiveness; training program; training assessment; bookkeeping, descriptive design

\section{Main text}

\section{Introduction}

Every organization whether large or small, private or public invest in training for their human resources. This is to enhanced the knowledge, skills and behaviour of their people so that they will work efficiently and effectively thereby contributing easily to the attainment of the goals and objectives of their respective organizations. But in order for the training to be effective, it must be relevant to the expertise or specialization or the need of the individual or group and it must be evaluated so that adjustments or changes be made for further training needs of employees.

There are many trainings offered by various firms and institutions out there. And Apayao State College is one of the many institutions offering trainings to individuals and organizations thru its extension unit. One of the most in-demand was the bookkeeping training which was yearly requested by different cooperatives in Conner, Apayao, barangay officials and concurrently the People's Organization of Conner, Apayao. Wherein the Bachelor of Science in Business Administration (BSBA) faculty were tapped as resource speakers.

The People's Organization of Conner, Apayao were came from different barangay of Conner, Apayao. They were organized in such a way to establish a livelihood programs in order for them to become self-reliant organization in the future. These organizations were provided with financial assistance by different government agencies to come up with programs/projects/activities in terms of investment. Thus, they were required to submit financial report of their investments. That is why officers of their respective organizations were even sponsored to attend different trainings and seminars to capacitate them. And one training identified was the bookkeeping training.

Bookkeeping training found to be useful for every organization in Conner, Apayao particularly for organizations which require other agencies of financial reporting. In addition, bookkeeping found to be a significant training program conducted by the Apayao State College that is why it is very important to assess this program to be able to identify its effectiveness, strengths and weaknesses and its applicability and adjustments for future bookkeeping trainings to be undertaken in the future. Hence, this study. 


\section{Theoretical Framework}

This study was guided with the theory:

Four levels of learning evaluation or the Kirkpatrick model (1950) is probably the best known model for analysing and evaluating the results of training and educational programs. It takes into account any style of training, both informal or formal, to determine aptitude based on four level criteria. Level 1 Reaction measures how participants react to the training. The objective of this level is straightforward, it evaluates how individuals react to the training by asking questions that establishes the trainees' thoughts. Questions will figure out if the participant enjoyed their experience and if they found the material in the program useful for their work. Level 2 Learning analyses if they truly understood the training. Evaluating at this level is meant to gauge the level participants have developed in expertise, knowledge, or mind set. Exploration at this level is far more-challenging. Level 3 Behaviour looks as if they are utilizing what they learned at work. This level analyses the differences in the participant's behaviour at work after completing the training. Assessing the change makes it possible to figure out if the knowledge, mind set, or skills the program taught are being used in the workplace. And Level 4 Results determines if the material had a positive impact. Commonly regarded as the primary goal of the training, the model can be implemented before, throughout, and following training to show the value of training.

Independent Variables

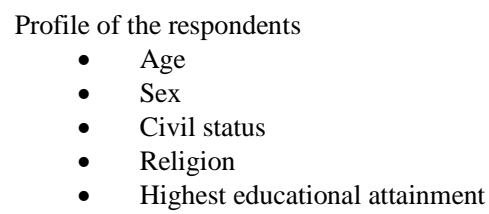

Assessment of respondents to bookkeeping training according to:

- Learner reaction

- Learning

- Behaviour

- Results

- Work efficiency
Dependent Variables

Effectiveness of the Bookkeeping Training Programs

Recommendations to enhance the Bookkeeping Training Program

Figure 1. Research paradigm

Research paradigm showed the independent and dependent variables. Independent variables start with the profile of the respondent in terms of age, sex, civil status, religion, and highest educational attainment. Then the effectiveness of the conducted bookkeeping training programs and lastly the recommendations to enhance the bookkeeping training program constituted the dependent variables.

\section{Statement of the Problem}

This study aimed to determine the assessment of the conducted bookkeeping training programs by the Apayao State College.

Specifically, this study sought answers the following questions:

1. What is the profile of the respondents in terms of:

1.1. Age

1.2. Sex

1.3. Civil status

1.4. Religion

1.5. Highest educational attainment

2. How do respondents' assess the bookkeeping training according to:

2.1. Learner Reaction

2.2. Learning

2.3. Behaviour 
2.4. Results

2.5. Work efficiency

3. What are the recommendations in order to enhance the bookkeeping training?

\section{Significance of the Study}

The following individual and groups could benefit to this study:

Apayao State College Top Management. That this study could continue sustain the funding and increasing the budget of extension programs conducted by all department.

BSBA Department and Faculty. That this study could motivate them to assess all extension programs to be conducted so that they can be able to enhanced or improved their delivery of public service to the clienteles.

Peoples Organization. That this study could serve as an eye opener for them to seriously participate all trainings to be provided and value it as an important activity.

Researcher. That this study could encourage him to conduct more researches.

Future researchers. That this study could help serve as basis or pattern for conducting study along similar lines.

\section{Scope and Delimitation of the Study}

This study was limited to the bookkeeping training programs conducted by the Apayao State College to the People's Organization in Conner, Apayao, 2019-2020, particularly on learner reaction, learning, behaviour, results and work efficiency.

\section{Definition of Terms}

Behaviour - this pertains to the improvement of attitude of the respondents towards work after the conducted training program.

Learning - this refers to the knowledge gain by the respondents from the bookkeeping training

Learner reaction - this pertains to how respondents evaluate the bookkeeping training program.

Results - the impact of the training program

Work efficiency - this pertains to the improvement of the bookkeeping skills of the respondents.

\section{Review of Related Literature}

An et. al (2015), learning as an outcome of the seminars and conferences attended would be utilized and observed through the improvement in job performance and attitude in terms of the perceived learning of the attendees, self-rating evaluation of their knowledge and skill level before and after the Learning and Development activities.

Basariya (2018), Training and development plays an important role in the effectiveness of organizations and to make experience people to do work effectively.

Engetou (2017), on the impact of employees' training and development on organizational performance revealed that training and development is a necessity in every companies particularly for the unskilled or the less experience employees. Generally, employees' work contribution was greatly improved due to the training methods and tools used by the company. Thus, it led to a positive impact on employee' performance and an improvement in their skills and job efficiency.

Farjad (2012), the evaluation of any training programme has certain aims to fulfil. These are concerned with the determination of change in the staff behaviour and the change needed in the organizational structure. Hence evaluation of 
any training program must inform us whether the training programme has been able to deliver the goals and objectives in terms of cost incurred and benefits achieved. Training as the process of developing skills, habits knowledge and attitudes in employees for the purpose of increasing effectiveness of employees in their present positions as well as preparing employees for future positions in organization.

Hajjar et. al (2018), training is a systematic way to improve the performance of employees, and it provides a link between job requirements and the current job specification of the employees. In addition, training requires time, energy, and money.

Raja et. al (2016), attempt to understand the opinion and attitudes of the various categories of employees towards the maintenance of effectiveness of training services provided by the company.

Saad et. al (2013), evaluation of training effectiveness is the measurement of improvement in the employee's knowledge, skill and behavioural pattern within the organization as a result of training program. This measurement help to match the cost incurred in the design and implementation of training with the associated benefits. Thus, it indicates whether the program has been able to deliver its intended goals and objectives.

Sahoo et al. (2014), organisations conduct the training programmes for the development of the human resources through the enrichment of knowledge, skills and attitude of the employees While designing the training programmes the objectives, methods/processes and the expected end results are well defined and planned relating to the topics and the target groups. Adequate care is taken before the programme to ensure the positive impact of the training on the participants so that the end result can be achieved as expected. Hence training evaluation is a must to assess the impact of the training on the participants leading to individual as well as organizational development. Training evaluation is required to assess the effectiveness of all the components of training programme.

Swain et. al (2014), evaluates the impact of widespread training programmes provided by the Self Help Group (SHG) programme. Further revealed the Non-Government Organization should be specialize in business training.

Timica (2017), workplace training programs are used to teach employees the knowledge and skills necessary to effectively perform on the job. These training programs are necessary for preparing staff to meet the demands of daily work expectations. The findings support the need to assess the training program and its users more thoroughly and frequently.

\section{Research Methodology}

\subsection{Research design}

This study used the descriptive survey method. This described the profile of the respondents . Also, it assessed the bookkeeping training according to learner reaction, learning, behaviour, results and work efficiency. Moreover, it identify some recommendations to enhance the bookkeeping training for preparation for future bookkeeping training to be conducted.

\subsection{Locale of the study}

This study was conducted in Conner, Apayao. Conner is one of the seven municipalities of the province of Apayao.

\subsection{Respondents and sampling procedure}

Respondents to this study are the (16) treasurers, (16) bookkeepers, (2) Site Management Officer and (2) Site Development Officer of the different Peoples Organization in Conner, Apayao. There were a total of thirty-six (36) respondents. Respondents were selected through total enumeration.

\subsection{Research instrument}

This study made use of the questionnaire consisted of three (3) parts. Part I dealt on the profile of the respondents. Part II on the assessment of the respondents according to learner reaction, learning, behaviour, results and work efficiency and Part III on the recommendations to enhance the bookkeeping training program. 


\subsection{Data gathering procedure}

A permission from the different People's Organization Presidents were sought. Then questionnaire were administered to the different participants of bookkeeping training. Then finally, the answered questionnaires were retrieved. Then answered questionnaires were consolidated, tabulated, analysed and interpreted.

\subsection{Analysis of data}

This study made used of the frequency and percentage distribution. It was used to describe the profile of the respondents and identify recommendations to enhance the bookkeeping training program. Moreover, weighted mean was employed to determine the assessment of the respondents to the conducted bookkeeping training programs as to learner reaction, learning, behaviour, results and work efficiency guided with a four-point scale as shown in legend below:

Table 1. Legend

\begin{tabular}{cll}
\hline Scale & \multicolumn{1}{c}{ Mean range } & \multicolumn{1}{c}{ Verbal interpretation } \\
\hline 4 & $4.0-4.99$ & Very Much Agree \\
3 & $3.0-3.99$ & Agree \\
2 & $2.0-2.99$ & Partly Agree \\
1 & $1.0-1.99$ & Disagree \\
\hline
\end{tabular}

\section{Discussion of Results}

Table 2 presents the profile of the respondents. As to age, majority of the respondents belong to age bracket 31 to 40 years old. Followed by age bracket 41 year old and above and lastly age bracket 20 to 30 years old. This implies that majority of the respondents were adult. As to sex, there were more female than male. This implies that female dominated the most number in joining to the different People's Organization in Conner, Apayao. As to civil status, majority of the respondents were married and the rest were single. This implies that most of the respondents were family men and women. As to religion, majority of the respondents belong to non-Catholic than Catholic. This implies that the respondents practiced catholic and non- catholic faith. And as to highest educational attainment, majority are bachelor's degree followed by high school graduate then Master's degree and lastly elementary graduate. This implies that majority of the respondents were highly educated to mention of finishing the tertiary level education and master's degree.

Table 2. Distribution of respondents according to profile

\begin{tabular}{|c|c|c|}
\hline Profile variables & Frequency & Percentage \\
\hline \multicolumn{3}{|l|}{ Age } \\
\hline 20 to 30 years old & 10 & $27.8 \%$ \\
\hline 31 to 40 years old & 16 & $44.4 \%$ \\
\hline $41-50$ & 8 & $22.2 \%$ \\
\hline 51 and above & 2 & $5.6 \%$ \\
\hline Total & 36 & $100 \%$ \\
\hline \multicolumn{3}{|l|}{ Mean age: 38} \\
\hline \multicolumn{3}{|l|}{ Sex } \\
\hline Male & 12 & $33.3 \%$ \\
\hline Female & 24 & $66.7 \%$ \\
\hline Total & 36 & $100 \%$ \\
\hline \multicolumn{3}{|l|}{ Civil status } \\
\hline Single & 7 & $19.4 \%$ \\
\hline Married & 29 & $80.6 \%$ \\
\hline Total & 36 & $100 \%$ \\
\hline \multicolumn{3}{|l|}{ Religion } \\
\hline Catholic & 10 & $27.8 \%$ \\
\hline
\end{tabular}




\begin{tabular}{|c|c|c|}
\hline Non-Catholic & 26 & $22.2 \%$ \\
\hline Total & 36 & $100 \%$ \\
\hline \multicolumn{3}{|l|}{ Highest educational attainment } \\
\hline Bachelor's degree & 16 & $44.4 \%$ \\
\hline Master's degree & 6 & $16.7 \%$ \\
\hline High school graduate & 12 & $33.3 \%$ \\
\hline Elementary graduate & 2 & $5.6 \%$ \\
\hline Total & 36 & $100 \%$ \\
\hline
\end{tabular}

Table 3. presents the learner reaction to the conducted bookkeeping training programs, where "resource speakers showed mastery of the subject matter" got the highest mean with a verbal interpretation of "very much agree". Followed by "resource speakers used variety of method or processed of the training such as lecture, discussion, workshops, etc."; "the methods used were effective and appropriate"; "resource speakers presented subject matter clearly" with a verbal interpretation of "agree" respectively. Then "resource speakers have the ability to aroused and sustained interest to the training" with a verbal interpretation of "agree". Next, "bookkeeping training provided new information, skills and relevance to my present work or job" with a verbal interpretation of "agree" and lastly, "there was an adequate instructional materials utilize during the training" also with a verbal interpretation of "agree". This implies that respondents "agree" to the different learner reaction to the conducted bookkeeping training programs with an average mean of 3.9. Tan, et. al (2013) said that reactions to training programs tend to be poor predictors of training success, yet most training programs are evaluated based solely on trainee reactions. These reactions may improve the prediction of trainee learning.

Table 3. Distribution of respondents according to learner reaction

\begin{tabular}{|c|c|c|}
\hline Learner reaction & Mean & Verbal interpretation \\
\hline $\begin{array}{l}\text { 1. Bookkeeping training provided new information, skills } \\
\text { and relevance to my present work or job. }\end{array}$ & \multirow{2}{*}{3.8} & agree \\
\hline $\begin{array}{l}\text { 2. There was an adequate instructional materials utilize } \\
\text { during the training. }\end{array}$ & & agree \\
\hline $\begin{array}{l}\text { 3. Resource speakers used variety of method or processed } \\
\text { of the training such as lecture, discussion, workshops, } \\
\text { etc. }\end{array}$ & 4.1 & very much agree \\
\hline 4. The methods used were effective and appropriate. & \multirow{2}{*}{4.1} & very much agree \\
\hline $\begin{array}{l}\text { 5. Resource speakers showed mastery of the subject } \\
\text { matter. }\end{array}$ & & very much agree \\
\hline 6. Resource speakers presented subject matter clearly. & 4.1 & very much agree \\
\hline $\begin{array}{l}\text { 7. Resource speakers have the ability to aroused and } \\
\text { sustained interest to the training. }\end{array}$ & \multirow{2}{*}{$\begin{array}{l}3.9 \\
3.9\end{array}$} & agree \\
\hline Average mean: & & agree \\
\hline
\end{tabular}

Table 4 presents the learning of the respondents to the conducted bookkeeping training programs and they were "agree“" particularly on "the training familiarized me and understand bookkeeping"; "the training improves my way of analysing business transactions"; "the training provides additional knowledge on understanding financial statement and bank reconciliation statement" and "the training improves my mathematical ability" with a mean of 3.9 respectively. This implies that respondents" "agree" or affirmed that they learned knowledge, skills and abilities on the conducted bookkeeping training programs. As such it enhances their capacity to perform the needed bookkeeping skills. Free management library viewed learning as new knowledge, skills and abilities. It enhances one's capacity to perform.

Table 4. Distribution of respondents according to learning

\begin{tabular}{|ccc|c|c|}
\hline \multicolumn{9}{|c|}{ Learning } & Mean & Verbal interpretation \\
\hline 1. The training familiarized me and understand & & \\
\hline
\end{tabular}




\begin{tabular}{|c|c|c|c|}
\hline & bookkeeping. & \multirow{3}{*}{$\begin{array}{l}3.9 \\
3.9\end{array}$} & \multirow{2}{*}{ agree } \\
\hline 2. & $\begin{array}{l}\text { The training improves my way of analysing business } \\
\text { transactions. }\end{array}$ & & \\
\hline 3. & $\begin{array}{l}\text { The training provides additional knowledge on } \\
\text { understanding financial statement and bank } \\
\text { reconciliation statement. }\end{array}$ & & agree \\
\hline 4. & The training improves my mathematical ability. & \multirow{2}{*}{$\begin{array}{l}3.9 \\
3.9 \\
3.9\end{array}$} & agree \\
\hline \multicolumn{2}{|c|}{ Average mean: } & & agree \\
\hline
\end{tabular}

Table 5 presents the behaviour of the respondents to the conducted bookkeeping training programs, "the training made me more responsible and honest person" and "the training made me to be more helpful with co-members/employees of the organization" got the highest mean with a verbal interpretation of "very much agree". Followed by "the training made me to be determined and committed to the job/work assigned to me" ; "the training made me to be more patient in doing my tasks/work/job" and "the training made me to make my work/job neat and organized" which have the same mean with a verbal interpretation also of "very much agree" respectively. This implies that respondents affirmed that there was a positive improvement in their behaviour towards work or assignment after the conducted bookkeeping training programs. Qayyum et. al (2011) explored the relationship between training program effectiveness and behaviour. As such, positive change in behaviour has something to do with the effectiveness of training programs.

Table 5. Distribution of respondents according to behaviour

\begin{tabular}{|c|c|c|}
\hline Behaviour & Mean & Verbal interpretation \\
\hline $\begin{array}{l}\text { 1. The training made me to be determined and committed } \\
\text { to the job/work assigned to me. }\end{array}$ & 4.5 & very much agree \\
\hline $\begin{array}{l}\text { 2. The training made me to be more patient in doing my } \\
\text { tasks/work/job. }\end{array}$ & 4.5 & very much agree \\
\hline $\begin{array}{l}\text { 3. The training made me to make my work/job neat and } \\
\text { organized. }\end{array}$ & 4.5 & very much agree \\
\hline $\begin{array}{l}\text { 4. The training made me more responsible and honest } \\
\text { person. }\end{array}$ & 4.6 & very much agree \\
\hline $\begin{array}{l}\text { 5. The training made me to be more helpful with co- } \\
\text { members/employees of the organization. }\end{array}$ & 4.6 & very much agree \\
\hline Average mean: & 4.5 & very much agree \\
\hline
\end{tabular}

Table 6 presents the results of the conducted bookkeeping training program, "objectives of the training were met" got the highest mean with a verbal interpretation of "very much agree". Followed by "the training contributed much to the knowledge and skills of the new tasks/work/job assigned to me" ; the training was efficiently and effectively managed"; "the venue of the training provided a good atmosphere" and "topics were organized and well-presented which have the same mean and with a verbal interpretation also of "very much agree" respectively. This implies that the results or objectives of the conducted bookkeeping training program were successfully met as affirmed by the respondents.

Table 6. Distribution of respondents according to results

\begin{tabular}{|c|c|c|}
\hline Results & Mean & Verbal interpretation \\
\hline $\begin{array}{l}\text { 1. The training contributed much to the knowledge and } \\
\text { skills of the new tasks/work/job assigned to me. }\end{array}$ & 4.5 & very much agree \\
\hline 2. The training was efficiently and effectively managed. & 4.5 & very much agree \\
\hline 3. The venue of the training provided a good atmosphere. & 4.5 & very much agree \\
\hline 4. Topics were organized and well-presented. & 4.5 & very much agree \\
\hline 5. Objectives of the training were met. & 4.6 & very much agree \\
\hline Average mean: & 4.5 & very much agree \\
\hline
\end{tabular}

Table 7 presents the work efficiency of the respondents, "I am applying the skills and information that I received from the Bookkeeping training in my current job" and "my familiarity with bookkeeping has improved" got the highest and the same 
mean with a verbal interpretation of "agree" respectively. Followed by "i can now analyse business transactions with ease" with a verbal interpretation of "agree". Next, "I can now prepare financial statement and bank reconciliation statement with confidence" with a verbal interpretation of "agree". And lastly, "my mathematical ability has improved also with a verbal interpretation of "agree". This implies that the work efficiency of the respondents in bookkeeping turned out to be better or have improved after the training. Ganesh et. al (2015) training and development plays an important role in the effectiveness of organizations and to make experience people to do work efficiently and effectively. It is said that training has implications for productivity, commitment to the work and personal development.

Table 7. Distribution of respondents according to work efficiency

\begin{tabular}{|c|c|c|}
\hline Work efficiency & Mean & Verbal interpretation \\
\hline $\begin{array}{l}\text { 1. I am applying the skills and information that I received } \\
\text { from the Bookkeeping training in my current job. }\end{array}$ & 3.9 & agree \\
\hline 2. My familiarity with bookkeeping has improved. & 3.9 & agree \\
\hline 3. I can now analyse business transactions with ease. & 3.8 & agree \\
\hline $\begin{array}{l}\text { 4. I can now prepare financial statement and bank } \\
\text { reconciliation statement with confidence. }\end{array}$ & 3.6 & agree \\
\hline 5. My mathematical ability has improved. & 3.5 & agree \\
\hline Average mean: & 3.7 & agree \\
\hline
\end{tabular}

Table 8 presents the recommendations of the respondents, "provide more exercises" got the highest frequency of 14 . Followed by "timeframe of the training program should be extended" with a frequency of 12 and finally "individual coaching should be done since there were elementary and high school level participants" with a frequency of 10 . This implies that these recommendations should be address to further enhance the bookkeeping training program.

Table 8. Distribution of respondents according to recommendations

\begin{tabular}{|l|c|c|}
\hline Recommendations & Frequency & Percentage \\
\hline 1. Time frame of the training program should be extended. & 12 & $33.3 \%$ \\
\hline 2. Provide more exercises. & 14 & $38.9 \%$ \\
\hline $\begin{array}{l}\text { 3. Individual coaching should be done since there were } \\
\text { elementary and high school level participants. }\end{array}$ & 10 & $27.8 \%$ \\
\hline Total & 36 & $100 \%$ \\
\hline
\end{tabular}

\section{Conclusion}

Based from the results of this study, it can be concluded that:

The conducted bookkeeping training programs by the Apayao State College was effective particularly on respondents' learner reaction, learning, behaviour, results and work efficiency. However, there are still areas that need to be enhanced or improved.

\section{Recommendation}

The following are recommended:

1. Sustain the effective way of conducting the bookkeeping training programs and incorporate the recommendations from the respondents particularly on:

a. duration of the training program should be extended

b. provide more exercises

c. individual coaching should be done since there were elementary and high school level participants 
2. Follow-up study will be conducted on the performance of the participants to include variables on the pre-test and post-test. 


\section{Acknowledgements}

The author would like to thank the following:

- Apayao State College - RDE Team for the usual support and cooperation;

- $\quad$ BSBA family for the friendship;

- His family especially his father - Papa Sen and mother - Mama Au and his loving wife Le and children - Mara, Ren, Arle and Danry for the understanding, love, joy and inspiration; and

- Above all to the Almighty Father who always guides and protect him and his family from the journey of life. 


\section{References}

An, I. L, Laguador, J. M., Portugal, L. M., 2015. Effectiveness of Training Program Among Liberal Arts Faculty Members in an Asian University. Asian Journal of Basic and Applied Sciences, 2(1).

Basariya, S. R., Sudhakar, R., 2018. Theoretical Framework on the Effectiveness of Training and Development. International Journal of Mechanical Engineering and Technology, 9(7), p. 932-943.

Engetou, E., 2017. The Impact of Training and Development on Organizational Performance, Centria University of Applied Sciences.

Farjad, S., 2012. The Evaluation Effectiveness of Training Courses in University: A Case Study. Procedia Social and Behavioral Sciences, 46, p. 2837-2841.

Hajjar, S.T., Alkhanaiz, M.S., 2018. Exploring the Factors that Affect Employee Training Effectiveness: A Case Study in Bahrain.

Raja, V. A., Kumar, R. A., 2016. A Study on Effectiveness of Training and Development in Ashok Leyland all over India. Journal of Management, 3(1), p. 01-12.

Saad, M., Mat, N. B., 2013. Evaluation of Effectiveness of Training and Development. Asian Journal of Business and Management, 2 (11), p. 14-24.

Sahoo et. al. (2014). Introduction organization to training program of human resource. Asian Journal of Social Sciences and Humanities, 4(9), p 56-63.

Swain, R. B., Varghese, A., 2014. Evaluating the Impact of Training in Self-help groups in India. European Journal of Development Research. p. 17.

Timica, E., 2017. Inside the VA: How Workplace Training Evaluation Impacts Employee Performance. Dissertations. 639. 